\title{
Evolution of electric field assisted dissolution of nanoparticles investigated by spectroscopic ellipsometry
}

\author{
Boris Okorn, Jordi Sancho-Parramon, Petar Pervan, Ivana Fabijanić, Vesna Janicki* \\ Ruđer Bošković Institute, Bijenička cesta 54, Zagreb, 10000, Croatia
}

\begin{abstract}
The evolution of electric field assisted dissolution (EFAD) of nanoparticles process is studied by means of spectroscopic ellipsometry. Multilayer structures with embedded Ag islands films are prepared by electron beam evaporation and subjected to EFAD process using different voltages and treatment times. Modelling of ellipsometric data evidences the dissolution process by the progressive quenching of the localized surface plasmon resonance of nanoparticles. Further quantitative information is revealed by the analysis of the effective dielectric function of $\mathrm{Ag}$ islands films in terms of the spectral density function. The amount of dissolved metal appears to follow a non-linear dependence with the applied voltage. Ag islands become elongated in the film plane as dissolution takes place. In the case of multiple $\mathrm{Ag}$ islands films, the process takes place in a sequential way, starting from the film closest to the glass substrate. Accumulation of Ag in a near-surface glass region is revealed by the presence of a refractive index gradient. Overall, the study demonstrates the usefulness of ellipsometry for providing novel insights into the EFAD process.
\end{abstract}

Keywords:

electric field assisted dissolution, metal nanoparticles, spectroscopic ellipsometry, localized surface plasmon resonance, refractive index gradient

\section{Introduction}

It has been shown that the combination of moderately elevated temperature and DC voltage results in the dissolution of metal nanoparticles embedded in or deposited on a dielectric matrix $[1,2,3]$. This electric field assisted dissolution (EFAD) process starts with the ionization of metal atoms that are then ejected from the nanoparticle into the dielectric matrix due to the applied voltage. The process continues until the nanoparticle is completely dissolved, being replaced by a nanopore. EFAD is closely related to glass poling [4] and it appears that the generation of an ion-depleted region in glass plays an important role for favouring particle dissolution [1].

The EFAD process has a strong application potential for it can largely modify the samples optical response as a result of quenching of the localized surface plasmon resonance (LSPR) of nanoparticles [5]. For instance, a sensing device that combines LSPR and wave-guiding effects has been produced using this method [6]. EFAD can be selectively applied using patterned electrodes, enabling the fabrication of two [7] and three [8] dimensional photonic structures. Sub-micron spatial resolution

*Corresponding author. E-mail: janicki@irb.hr 
can be achieved using this approach $[9,10]$. Recently, the EFAD method has been combined with glass poling to microstructure compact metal films [11].

In order to fully exploit the application possibilities of EFAD, it is essential to determine the evolution of sample properties as the process takes place. Additionally, a better understanding of EFAD dynamics shall permit to validate and extend theoretical models that have been proposed to describe the process [12]. Electrical measurements and compositional analysis were initially used to obtain a qualitative description of the process evolution $[1,2,3,5]$. A more precise picture was later obtained by application of EFAD with different parameter values (voltage, temperature and treatment time). Thus, optical extinction measurements allow quantifying the LSPR quenching and correlating it with the concentration of undissolved nanoparticles [13, 14]. Electron microscopy has been used to investigate shape modifications of Au nanorods [15] and nano-spheres [16] at different EFAD conditions.

In the present work we analyse the evolution of metal nanoparticle films subjected to the EFAD process using spectroscopic ellipsometry. Different voltages or treatment times have been applied to multilayer structures containing single or several Ag islands films deposited on glass substrates. We show that the high sensitivity of ellipsometry to sample structural changes [17] enables a detailed insight on the dissolution process evolution. In particular, quantitative information regarding concentration and shape distribution of undissolved nanoparticles is obtained by analysing the effective dielectric function of $\mathrm{Ag}$ islands films in terms of the spectral density function theory. In samples with several $\mathrm{Ag}$ islands films the dissolution process appears to occur sequentially, starting in the films closer to the substrate. Finally, Ag diffusion into the glass is revealed by the formation of a refractive index gradient in the near-surface substrate region. Overall, this study shows that accurate modelling and analysis of ellipsometric data can bring detailed information that helps in understanding EFAD dynamics and in tailoring the samples optical response.

\section{Experimental}

$\mathrm{Ag}-\mathrm{SiO}_{2}$ multilayers were deposited on microscopic glass slides (VWR, $1 \mathrm{~mm}$ thick) by electron beam evaporation using a modified Varian chamber. Samples with different structures were fabricated: i) $\mathrm{SiO}_{2} / \mathrm{Ag} / \mathrm{SiO}_{2} /$ glass, ii) $\mathrm{SiO}_{2} /\left(\mathrm{Ag} / \mathrm{SiO}_{2}\right)^{2} /$ glass and iii $)\left(\mathrm{Ag} / \mathrm{SiO}_{2}\right)^{4} /$ glass, all $\mathrm{SiO}_{2}$ and $\mathrm{Ag}$ films having $90 \mathrm{~nm}$ and $15 \mathrm{~nm}$ mass thickness, respectively. Several samples of each kind were produced in the same depostion run in order to apply different EFAD process parameters to identical samples. The amount of deposited material was controlled using a quartz crystal monitor. Substrates were pre-heated at $250{ }^{\circ} \mathrm{C}$ in order to enhance the Volmer-Weber growth of $\mathrm{Ag}$ islands on dielectric surfaces and obtain films consisting of isolated Ag nanoparticles [18]. The base pressure was about $6 \times 10^{-6}$ Torr and the deposition rate was kept at $\approx 1 \AA / \mathrm{s}$.

The fabricated samples were subjected to the EFAD process by application of different DC voltages $(V)$ in the range between 200 and $500 \mathrm{~V}$ at $200{ }^{\circ} \mathrm{C}$. A glass plate coated with Cr layer was used as anode in order to ensure smooth contact with the multilayer surface. In order to secure that the samples reached the set temperature, they were pre-heated for 1 hour before the voltage application. After a given time (between $1.25 \mathrm{~min}$ and $15 \mathrm{~min}$ ), the applied voltage was disconnected and the samples were left to cool down to room temperature.

Spectroscopic ellipsometric measurements of untreated and treated samples were taken with a J. A. Woollam V-VASE ellipsometer in the range $0.57-4.5 \mathrm{eV}$ at different angles of incidence $\left(45^{\circ}\right.$, $55^{\circ}$ and $65^{\circ}$ ). The WVASE software was used to model the samples and to fit ellipsometric data, 
as described in the next section. Secondary ion mass spectrometry (SIMS) measurements were performed on selected samples to confirm the insights from ellipsometric data analysis.

\section{Theory}

\subsection{Sample modelling and ellipsometric data fitting}

A first-principle calculation of metal island films optical properties is very complex due to the irregular islands shape and size distribution and the electromagnetic coupling among particles. However, when metal islands are much smaller than the light wavelength the islands film can be treated as a homogeneous layer with optical response fully determined by an effective dielectric function $\left(\varepsilon_{e f f}\right)$. Previous research has shown that a multiple oscillator model can adequately

represent $\varepsilon_{e f f}$ of metal islands films embedded in a dielectric matrix [19, 20,21]. Thus, we use the following dispersion model:

$$
\varepsilon_{e f f}(E)=\varepsilon_{\infty}+\sum_{k=1}^{n}\left[\varepsilon_{G R, k}(E)+i \varepsilon_{G I, k}(E)\right]
$$

with

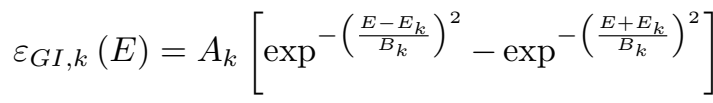

$$
\begin{aligned}
& \varepsilon_{G R, k}(E)=\frac{2}{\pi} P \int_{0}^{\infty} \frac{\xi \varepsilon_{G I, k}(\xi)}{\xi^{2}-E^{2}} d \xi
\end{aligned}
$$

where $E$ is the photon energy. The parameter $\varepsilon_{\infty}$ is the contribution of polarization mechanisms occurying at photon energies above the measured spectral range. The second term is a sum of Gaussian oscillators that can account for the LSPR of metal islands and Ag interband transitions. Gaussian oscillators appear to be superior to the classical Lorentzian model for systems like metal islands films, in which the size and shape distribution of particles often results into a nearly Gaussian resonances distribution [21]. Each Gaussian oscillator is defined through its amplitude $\left(A_{k}\right)$, central energy $\left(E_{k}\right)$ and broadening $\left(B_{k}\right)$. In the present study, one to two oscillators are necessary to describe the islands LSPR and one additional oscillator is required for the interband transition appearing around $4 \mathrm{eV}$.

Optical constants of pure materials (glass, $\mathrm{Ag}$ and $\mathrm{SiO}_{2}$ ) that were used in modelling the ellipsometric measurements were determined by characterization of bare substrates and bulk-like layers. Thus, the parameters to be optimized through experimental data fitting were the multiple-oscillator parameters for $\varepsilon_{e f f}$ of $\mathrm{Ag}$ islands films, their effective thickness $\left(d_{e f f}\right)$, thicknesses of $\mathrm{SiO}_{2}$ films and, if needed, parameters defining a refractive index profile gradient in a near-surface glass region. The fitting procedure was carried out using the WVASE software and led to the parameters optimal values by minimization of the mean square error that quantifies the discrepancy between measured and simulated data.

\subsection{Spectral density theory}

Classical effective medium theories describe $\varepsilon_{e f f}$ of a composite in terms of the constituent materials dielectric functions and a limited set of geometrical parameters, typically the volume fraction and depolarization factor of inclusions. Therefore these theories overlook the morphological complexity of metal islands films [18]. Advanced models that explicitly take into account the 
statistical distribution of islands are necessary for an accurate description of the experimentally observed optical response [22]. Yet, a general expression for any effective medium theory of a two-component composite is given by the spectral density theory [23]. This theory states that the effective dielectric function can be expressed in the following integral representation:

$$
\varepsilon_{e f f}=\varepsilon_{a}\left(1-f \int_{0}^{1} \frac{g(u)}{t-u} d u\right) \quad \text { with } \quad t=\frac{\varepsilon_{a}}{\varepsilon_{a}-\varepsilon_{b}}
$$

where $\varepsilon_{a}$ and $\varepsilon_{b}$ are the dielectric functions of the host and the inclusions, $f$ is the volume fraction of inclusions, $u$ is the integration variable and $g(u)$ is the so-called spectral density function. This expression enables separating the role of the system geometry, contained in $g(u)$, and of the dielectric function of components, appearing only in $t[24,18]$. In the case of an spatially ordered composite made of spherical inclusions the spectral density is a $\delta$ function centred at $(1-f) / 3$, indicating that for $f \rightarrow 0$ the system will have a resonance when $\varepsilon_{b}=-2 \varepsilon_{a}$, that corresponds to the LSPR condition for small spherical particles. This resonance shifts to more negative values of $\varepsilon_{b}$ when $f$ increases, explaining the LSPR red-shift caused by electromagnetic coupling among particles. Disorder, size and shape distributions result in local field fluctuations that broaden the spectral density function and hence the LSPR. If $\varepsilon_{e f f}, \varepsilon_{a}$ and $\varepsilon_{b}$ are known, both $f$ and $g(u)$ can be numerically inferred, i.e. information on the morphological characteristics of the sample can be retrieved from optical measurements [18, 21, 25].

\section{Results and discussion}

\subsection{Ag islands single films}

The EFAD process dynamics in single $\mathrm{Ag}$ islands films was investigated by applying different voltages (200 to $500 \mathrm{~V}$ ) to the $\mathrm{SiO}_{2} / \mathrm{Ag} / \mathrm{SiO}_{2} /$ glass samples. In all the cases the treatment time was 2.5 minutes. Ellipsometric data fitting was performed by optimization of $\mathrm{Ag}$ islands films $\varepsilon_{e f f}$ and $d_{e f f}$ and the thickness value of the top $\mathrm{SiO}_{2}$ film $\left(d_{\mathrm{SiO}_{2}}\right)$. The value of this last parameter is expected to be lower than the deposited mass thickness because part of $\mathrm{SiO}_{2}$ fills the space between $\mathrm{Ag}$ particles. In a first step the measurements of all samples are simultaneously fitted imposing $d_{\mathrm{SiO}_{2}}$ and $d_{e f f}$ to be the same in all samples by parameter coupling. This assumption is justified by the fact that samples were deposited in the same run and helps to reduce multiplicity of solutions and statistical uncertainty of the optimization parameters [26]. For the final solution $d_{\text {eff }}$ was allowed to vary from sample to sample, leading to slightly improved fittings i.e. the mean square error was reduced by $\approx 10 \%$.

Experimental data and fits for a sample that is representative of the typical fitting quality are shown in Figure 1. The variation of $\varepsilon_{e f f}$ with the applied voltage is presented in Figure 2 and a summary of the final values of the obtained parameters is given in Table 1. Here the LSPR position $\left(E_{L S P R}\right)$ is defined as the photon energy where the imaginary part of $\varepsilon_{e f f}$ presents its maximum value $\left(\Im \varepsilon_{e f f_{L S P R}}\right)$. It is observed that the LSPR shifts to larger photon energies and reduces its intensity when the applied voltage is increased. Both of these trends can be explained by a reduction of the overall amount of $\mathrm{Ag}$ in the shape of nanoparticles in accordance with the known fact that that the dissolution process is stronger for larger $V$ values [13, 14]. In general, $d_{\text {eff }}$ reduces with $V$. Indeed, it has been suggested that when nanoparticles dissolve they leave nanopores in the matrix [27] that can partially collapse and reduce its thickness [8]. Finally, $d_{\mathrm{SiO}_{2}}$ was found to be $81.5 \mathrm{~nm}$, as expected lower than the amount of deposited material. 

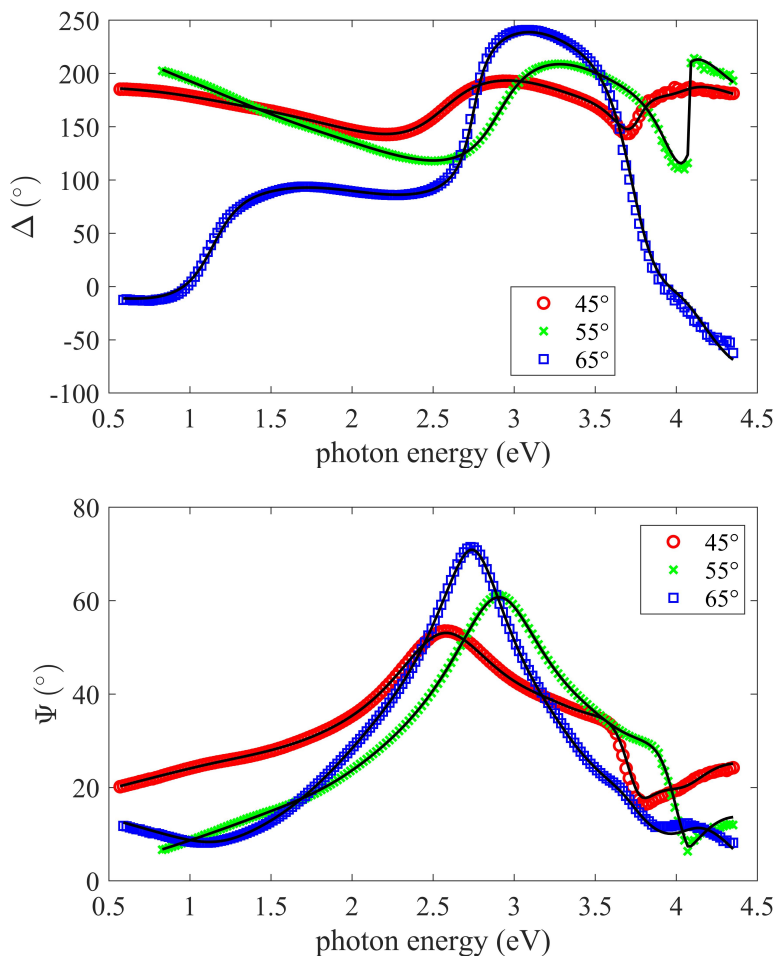

Figure 1: Ellipsometric functions (top: $\Delta$, bottom: $\Psi$ ) at different angles of incidence for the sample with a single $\mathrm{Ag}$ islands film treated with $V=300 \mathrm{~V}$ for $2.5 \mathrm{~min}$. Experimental measurements are represented by symbols and best fits by solid lines.

\begin{tabular}{cccccc}
$V(\mathrm{~V})$ & $d_{\text {eff }}(\mathrm{nm})$ & $f_{A g}$ & $d_{\text {mass }}(\mathrm{nm})$ & $E_{L S P R}(\mathrm{eV})$ & $\Im \varepsilon_{\text {eff }}$ LSPR \\
\hline untreated & 31.5 & 0.47 & 14.7 & 2.12 & 33.2 \\
200 & 28.0 & 0.43 & 12.1 & 2.20 & 17.5 \\
300 & 25.7 & 0.31 & 7.8 & 2.42 & 8.6 \\
400 & 27.7 & 0.21 & 5.9 & 2.52 & 4.90 \\
500 & 25.0 & 0.14 & 3.4 & 2.65 & 2.74
\end{tabular}

Table 1: Summary of parameters inferred from ellipsometric data fits and spectral density analysis for the samples with single $\mathrm{Ag}$ islands film treated at different voltages $(V)$ for $2.5 \mathrm{~min}$ : effective thickness $\left(d_{e f f}\right), \mathrm{Ag}$ volume fraction in the $\mathrm{Ag}$ islands film $\left(f_{A g}\right)$, equivalent $\mathrm{Ag}$ mass thickness in the composite $\left(d_{m a s s}\right)$, position $\left(E_{L S P R}\right)$ and value of the imaginary part of $\varepsilon_{\text {eff }}\left(\Im_{\text {eff } L S P R}\right)$ at the surface plasmon resonance peak. 

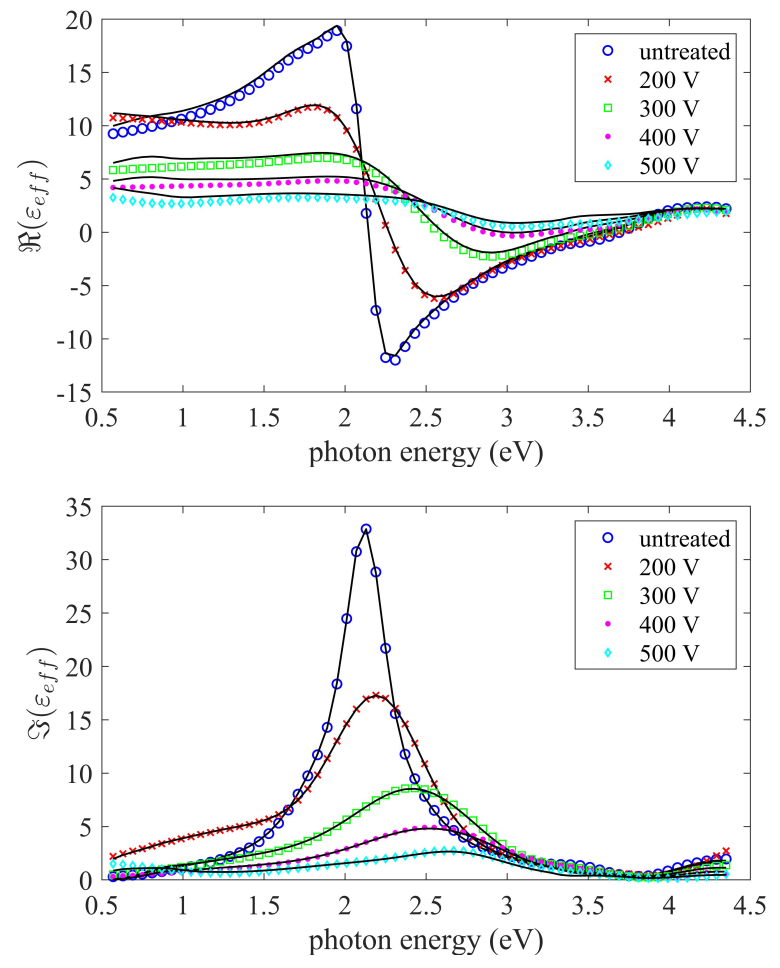

Figure 2: Effective dielectric function (top: real part, bottom: imaginary part) for the $\mathrm{Ag}$ islands films in $\mathrm{SiO}_{2} / \mathrm{Ag} / \mathrm{SiO}_{2} /$ glass samples as a function of the applied voltage. Symbols represent data extracted from ellipsometric measurements and solid lines are the corresponding best fits obtained by numerical inversion of the spectral density function.

The metal filling fraction $\left(f_{A g}\right)$ and the spectral density function of Ag islands films was determined by numerical inversion of Equation 4, modelling these films as $\mathrm{SiO}_{2}$ host - $\mathrm{Ag}$ inclusions composites. The obtained spectral density functions are shown in Figure 3 and the values of $f_{A g}$ are collected in Table 1 . The agreement between the experimentally determined $\varepsilon_{\text {eff }}$ and those generated with the spectral density functions is shown in Figure 2. As it was expected $f_{A g}$ reduces and the geometrical resonances shift when the applied voltage increases. It is also observed that the spectral density function largely broadens with $V$. Since $f_{A g}$ and, consequently, the interaction among particles reduce with $V$, the observed broadening must be related to islands morphology modifications. Taking into account that size distribution affects only moderately the spectral density function and $\varepsilon_{\text {eff }}[28,29,30]$, the broadening suggests important shape modifications during the EFAD process. In particular, the particles should become in average more elongated during dissolution. An ellipsoidal particle provides two different resonances for polarizations parallel to its short and long axis. The depolarization factor and hence the spectral separation between the resonances becomes larger as the particle aspect ratio increases. Therefore, a random distribution of particles elongated in the film plane can provide a wide range distribution of depolarization factors [31] and explains the observed spectral density function broadening. This analysis agrees with the results of previous electron microscopy studies [16] proving that spherical particles acquire an elongated lunar-eclipselike structure as the dissolution process takes place. The quantity 
$d_{\text {mass }}=f_{A g} \cdot d_{\text {eff }}$ can give an estimate of the total amount of undissolved Ag (Table 1), that continuously decreases with $V$. It appears that $d_{\text {mass }}$ reduces only $18 \%$ under the application of $200 \mathrm{~V}$ and that afterwards the decrease of undissolved $\mathrm{Ag}$ with $V$ is much faster (72\% from 200 to $500 \mathrm{~V}$ ), showing the non-linearity of the EFAD process with the applied voltage and suggesting the existence of a threshold $V$ for dissolution to begin effectively [1, 13].

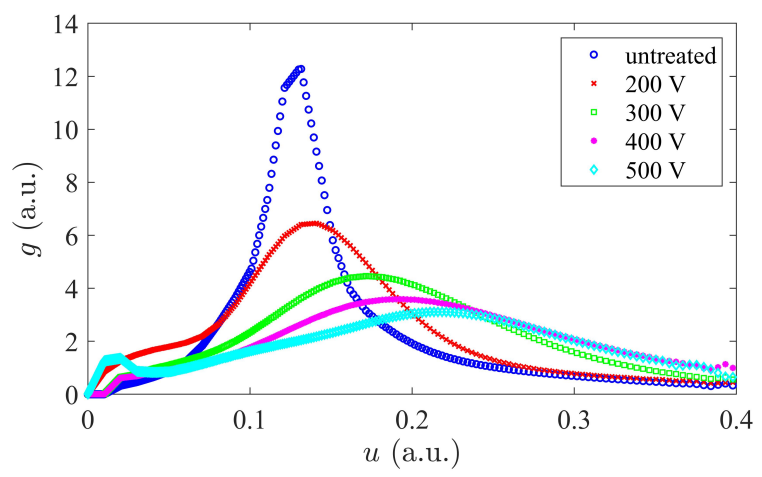

Figure 3: Spectral density function obtained by numerical inversion of the effective dielectric function of $\mathrm{Ag}$ islands films in $\mathrm{SiO}_{2} / \mathrm{Ag} / \mathrm{SiO}_{2} /$ glass samples treated with different voltages.

\subsection{Ag islands multilayers}

Next, the samples with two $\mathrm{Ag}$ islands films, i.e. $\mathrm{SiO}_{2} /\left(\mathrm{Ag} / \mathrm{SiO}_{2}\right)^{2} /$ glass structures, were investigated. In these samples the voltage was fixed at $500 \mathrm{~V}$ and the treatment time was varied between 1.25 and $10 \mathrm{~min}$. It was necessary to allow the top and bottom $\mathrm{Ag}$ islands films to have different $\varepsilon_{e f f}$ in order to account for in-depth inhomogeneity of the dissolution process. This requirement significantly increases the number of parameters to be optimized and restrictions were set in order to avoid multiplicity of solutions. Thus, $d_{\text {eff }}$ was forced by parameter coupling to have the same value for all $\mathrm{Ag}$ islands films since, as mentioned before, variation of $d_{e f f}$ with the treatment conditions leads only to a moderate improvement of the fitting quality. In addition, it was imposed parameter coupling for the thickness of top $\mathrm{SiO}_{2}$ film and for the one of the middle $\mathrm{SiO}_{2}$ films for all samples.

Measured ellipsometric data and corresponding fits for the sample treated for 1.25 minutes is shown in Figure 4. The LSPR characteristics of the Ag island films are summarized in Table 2. LSPR was absent in $\varepsilon_{e f f}$ for bottom islands films treated 5 minutes or longer and for the top islands film treated for 10 minutes, revealing complete film dissolution. The spectral dependence of $\varepsilon_{\text {eff }}$ for the other Ag islands films is shown in Figure 5. Same as in the case of single Ag films, there is a progressive quenching and blue-shift of the LSPR with dissolution. Furthermore, these changes are faster for the bottom $\mathrm{Ag}$ film than for the top one. The $d_{\text {eff }}$ parameter was found to be 28.6 $\mathrm{nm}$. The top and middle $\mathrm{SiO}_{2}$ layers thicknesses were 81.0 and $77.4 \mathrm{~nm}$ respectively.

The spectral density function and $f_{A g}$ (Table 2) of the islands films were inferred from $\varepsilon_{e f f}$ in the same manner as described above. Like in the previous case, the spectral density function (not shown) shifts and broadens with the EFAD process, suggesting the same morphological changes discussed above. It can be seen that the amount of undissolved $\mathrm{Ag}\left(d_{\text {mass }}\right)$ in the top Ag islands film remains nearly constant until the bottom layer is fully dissolved. Thus, the time evolution of $d_{\text {mass }}$ suggests that the EFAD process takes place in a layer-by-layer sequential way, starting from 
the islands film closer to the substrate. It should be noted that this conclusion cannot be directly deduced from the characteristics of $\varepsilon_{e f f}$ alone: the changes on the LSPR of the top Ag islands film for the samples treated for 1.25 and 2.5 min with respect to the untreated sample LSPR could be understood as a signature of dissolution. In fact this difference can be explained by temperature effects. Even if there is no dissolution, the samples are subjected to annealing that can lead to an increased sphereicity of Ag islands and a subsequent LSPR blue-shift. Indeed, the same kind of samples exposed to the same EFAD temperature and treatment time conditions including preheating have islands films $\varepsilon_{\text {eff }}$ very close to the one obtained for the top Ag islands films treated with EFAD for 1.25 and 2.5 minutes.
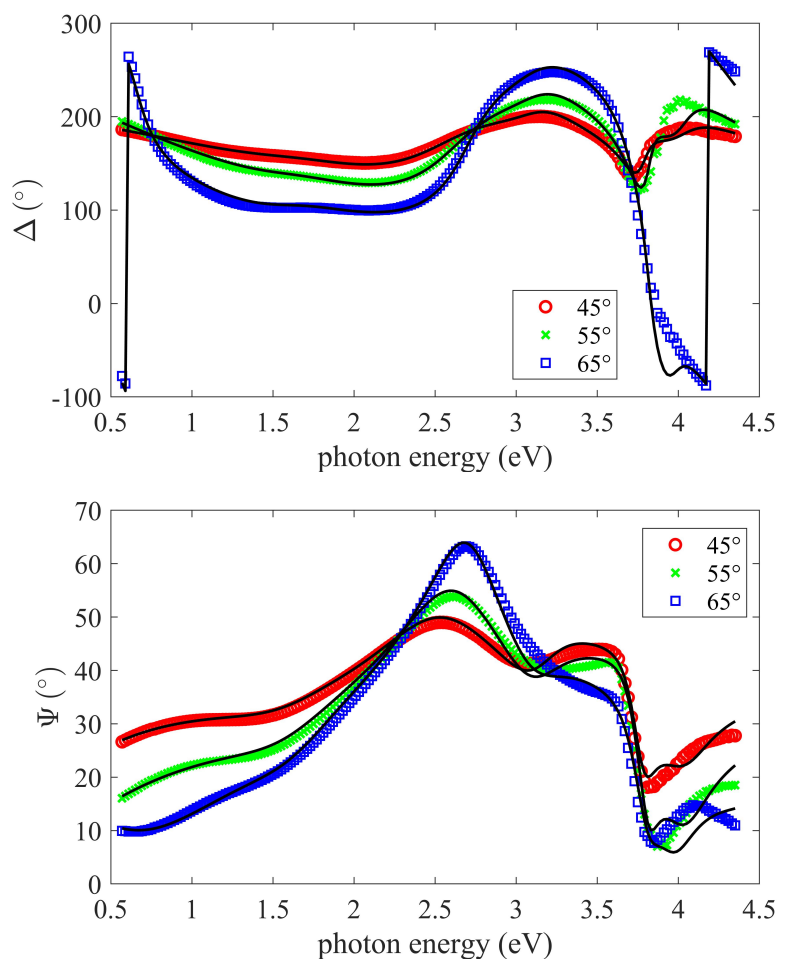

Figure 4: Ellipsometric functions (top: $\Delta$, bottom: $\Psi$ ) at different angles of incidence for the sample with two Ag islands films treated with $V=500 \mathrm{~V}$ for $1.25 \mathrm{~min}$. Experimental measurements are represented by symbols and best fits by solid lines. 


\begin{tabular}{ccccc}
$t(\min )$ & $f_{A g}$ & $d_{\text {mass }}(\mathrm{nm})$ & $E_{L S P R}(\mathrm{eV})$ & $\Im \varepsilon_{\text {eff }} L S P R$ \\
\hline untreated & $0.47 / 0.47$ & $13.5 / 13.5$ & $2.18 / 2.18$ & $23.9 / 23.9$ \\
1.25 & $0.42 / 0.24$ & $12.1 / 6.8$ & $2.29 / 2.50$ & $15.6 / 5.6$ \\
2.5 & $0.41 / 0.13$ & $11.8 / 3.6$ & $2.29 / 2.63$ & $15.7 / 2.1$ \\
5 & $0.24 / 0$ & $6.8 / 0$ & $2.55 /-$ & $6.64 /-$ \\
7.5 & $0.04 / 0$ & $1.0 / 0$ & $2.54 /-$ & $0.6 /-$ \\
10 & $0 / 0$ & $0 / 0$ & $-/-$ & $-/-$
\end{tabular}

Table 2: Summary of parameters inferred from ellipsometric measurements fits and spectral density analysis for the samples with two $\mathrm{Ag}$ islands films treated for different times $(t)$ at $500 \mathrm{~V}: \mathrm{Ag}$ volume fraction in the top and bottom $\mathrm{Ag}$ islands film $\left(f_{A g}\right)$, equivalent $\mathrm{Ag}$ mass thickness in the composite $\left(d_{\text {mass }}\right)$, position $\left(E_{L S P R}\right)$ and value of the imaginary part of $\varepsilon_{\text {eff }}\left(\Im_{\text {eff } L S P R}\right)$ at the surface plasmon resonance peak. The first and second number in the columns refer to the top and bottom islands films respectively.
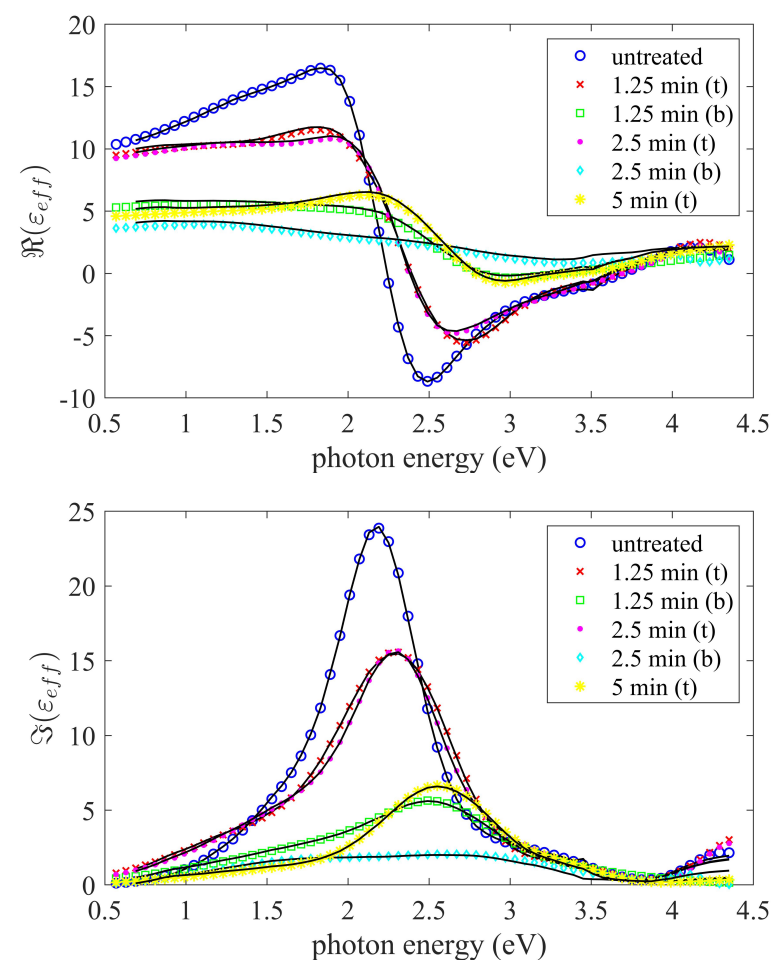

Figure 5: Effective dielectric function (top: real part, bottom: imaginary part) for the Ag islands film for the samples with two $\mathrm{Ag}$ islands films treated with different times at $V=500 \mathrm{~V}$. Symbols represent data extracted from ellipsometric measurements and solid lines are the corresponding best fits obtained by numerical inversion of the spectral density function. $(t)$ and $(b)$ refer to the top and bottom islands films respectively.

Quality of ellipsometric measurements fitting for the samples treated for 7.5 and $10 \mathrm{~min}$ was worse than for the rest of the samples. No significant improvement was obtained when the previously mentioned restriction on $d_{e f f}$ was removed. Taking into account that the dissolution process 
was very advanced for these samples, $\mathrm{Ag}$ ions ejected from the nanoparticles may affect the optical properties of the dielectric surroundings: $\mathrm{SiO}_{2}$ films and glass region next to the multilayer. Accordingly, the sample model was extended by: i) allowing the refractive index of $\mathrm{SiO}_{2}$ films to vary and ii) incorporating a region near the substrate surface where the dielectric function could vary with depth, i.e. a refractive index gradient. The fitting quality was improved with these modifications, reducing to half the mean square error. The resulting dielectric function depth profiles for both samples are shown in Figure 6. Only the bottom $\mathrm{SiO}_{2}$ film dielectric function slightly increased. The dielectric function of the glass substrate presents a peak in a near-surface region. Both of these characteristics can be explained by the accumulation of Ag ions, resulting in a localised refractive index increase [32]. The refractive index gradient for the sample treated for 10 minutes is shifted deeper into the glass substrate with respect to the sample treated for 7.5 minutes, indicating a deeper implantation of $\mathrm{Ag}$ ions with longer treatment. Lastly, it should be noted that the films that contained $\mathrm{Ag}$ islands have $\varepsilon_{\text {eff }}$ that are purely real and with values below those of $\mathrm{SiO}_{2}$ films, confirming the porosity of these zones.

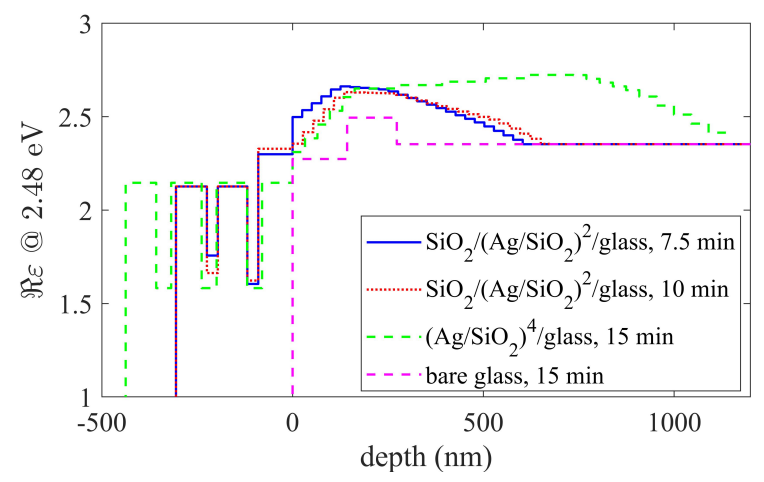

Figure 6: Dielectric function real part depth profile for different treated samples. The multilayer/glass interface is located at $0 \mathrm{~nm}$, i.e. positive values belong to the substrate and negative values to the multilayer. The rightmost part with constant dielectric function represents unchanged glass.

In order to confirm the formation of a refractive index gradient upon particle dissolution, an even longer EFAD treatment was applied to samples with a larger amount of Ag. Thus, samples with structure $\left(\mathrm{Ag} / \mathrm{SiO}_{2}\right)^{4} /$ glass were subjected to $500 \mathrm{~V}$ up to 15 minutes. Due to the number of $\mathrm{Ag}$ islands films in this structure it was not possible to find $\varepsilon_{\text {eff }}$ independently for each film: due to large absorption, the influence of deeper $\mathrm{Ag}$ islands in the measured spectra was weak. Instead, assuming that all but the outermost Ag islands film have the same $\varepsilon_{\text {eff }}$, reasonably good fittings were obtained. Ellipsometric data and corresponding fits for the untreated sample and for the sample treated for 15 minutes are shown in Figure 7. The total thickness of the multilayer structure decreases from $497 \mathrm{~nm}$ for the untreated sample to $440 \mathrm{~nm}$ for the sample treated for 15 minutes. It should be noted that outside of the LSPR region, the spectra of the untreated sample show high amplitude interference fringes due to the large dielectric function contrast between $\mathrm{SiO}_{2}$ and $\mathrm{Ag}$ islands films. On the other hand, the spectra of the sample treated for 15 minutes show a dual modulation in the whole measured spectral range: one of moderate amplitude and large period that can be associated to the porous multilayer structure and another with weak amplitude and small period that indicates the presence of a thick region with refractive index slightly different 
from the one of its surrounding. The dielectric function profile for this sample (Figure 6) confirms the presence of a refractive index gradient inside the glass that is thicker and has a deeper peak than those obtained for samples with two Ag islands films. It should be pointed out that a refractive index gradient also appears in bare glass substrates treated at $500 \mathrm{~V}$ for 15 minutes. This gradient essentially originates from a glass region where alkali ions contained in glass have redistributed drifting towards the cathode upon application of an external electric field. This redistribution, known as glass poling, modifies the optical properties of the substrate near-surface region less than by implantation of $\mathrm{Ag}$ ions in the case of the studied samples.
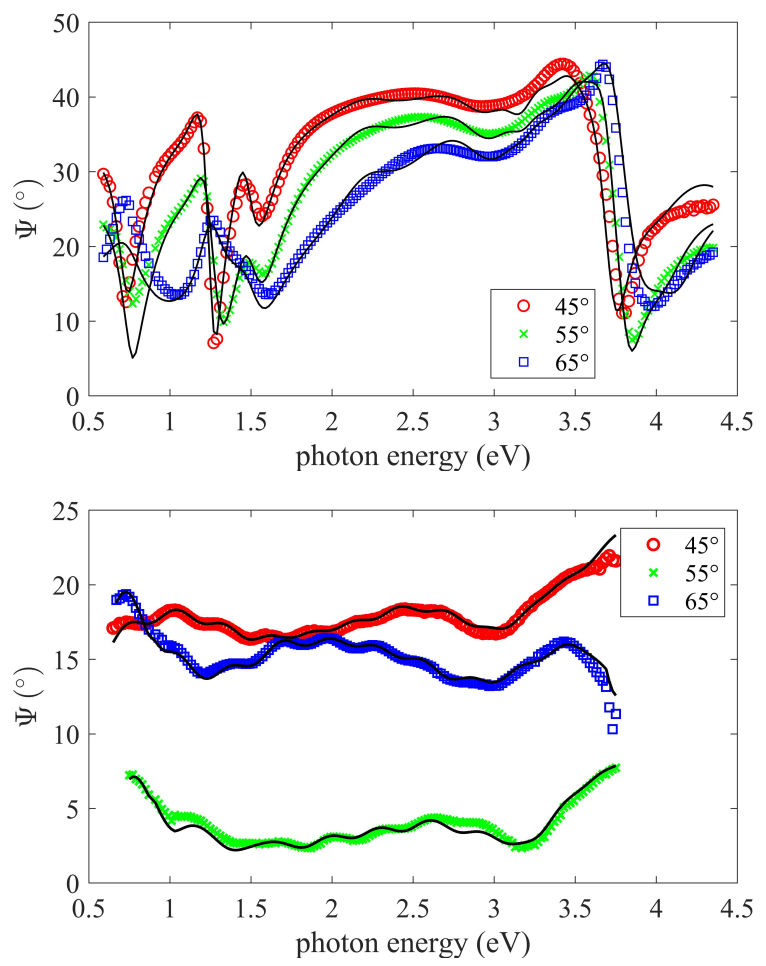

Figure 7: Ellipsometric function $\Psi$ at different angles of incidence for the sample with $4 \mathrm{Ag}$ islands films as untreated (top) and treated with $V=500 \mathrm{~V}$ for $15 \mathrm{~min}$ (bottom). Experimental measurements are represented by symbols and best fits by solid lines.

Finally, in order to confirm the observations extracted from analysis of ellipsometric data, SIMS measurements were carried out on the just discussed $\left(\mathrm{Ag} / \mathrm{SiO}_{2}\right)^{4} /$ glass samples treated for different times (Figure 8). It is shown that: i) the dissolution starts from the $\mathrm{Ag}$ islands films closer to the substrate and that the other Ag islands films are weakly modified until this layer becomes completely dissolved ii) accumulation of dissolved $\mathrm{Ag}$ takes place in the near-surface region of the glass substrate but not in $\mathrm{SiO}_{2}$ films away from the glass/multilayer interface, and iii) the overall thickness of the multilayer structure is reduced as the EFAD process progresses. 


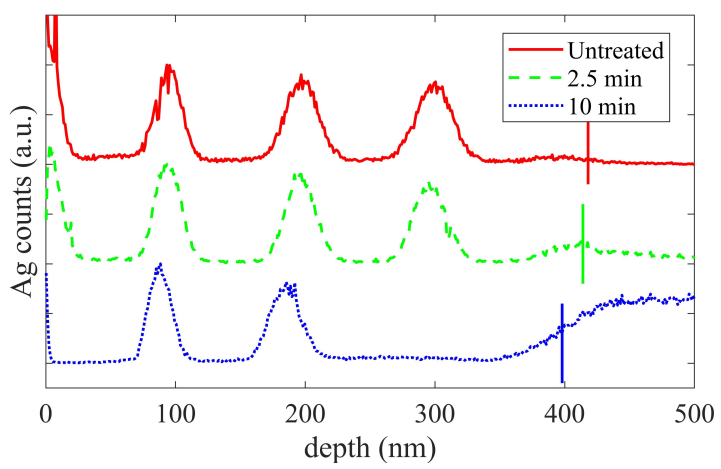

Figure 8: SIMS Ag counts for the $\left(\mathrm{Ag} / \mathrm{SiO}_{2}\right)^{4} /$ glass samples subjected to EFAD with $V=500 \mathrm{~V}$ and different treatment times. Vertical lines around $400 \mathrm{~nm}$ indicate the multilayer/glass interface determined from SIMS measurements of $\mathrm{Al}$ atoms, present in glass but not in the multilayer. Counts are shifted in the $y$ axes by a constant value for easier comparison.

\section{Conclusions}

Electric field assisted dissolution of nanoparticles in multilayer coatings that contain Ag island films is investigated by spectroscopic ellipsometry. Sample modeling permits tracking the evolution of the dissolution process, showing the progressive quenching of the plasmon resonance of metal islands, the reduction of the total thickness and the formation of a refractive index profile in the glass substrate near-surface region different from the one of poled glass. A deeper analysis of the results based on the spectral density theory allows quantifying the amount of undissolved $\mathrm{Ag}$ and reveals that the dissolution process is not homogeneous but takes place in a sequential way and that particles become more elongated as they dissolve. Being a non-destructive technique, spectroscopic ellipsometry appears as a useful tool to investigate the sample structural modifications happening during EFAD and bring new insights on the process dynamics.

\section{Acknowledgements}

This work was financed by the Croatian Science Foundation under the project no. IP-2016-062168.

\section{References}

[1] A. Podlipensky, A. Abdolvand, G. Seifert, H. Graener, O. Deparis, P. Kazansky, Dissolution of silver nanoparticles in glass through an intense dc electric field, The Journal of Physical Chemistry B 108 (46) (2004) 17699-17702.

[2] F. P. Mezzapesa, I. C. Carvalho, P. G. Kazansky, O. Deparis, M. Kawazu, K. Sakaguchi, Bleaching of sol-gel glass film with embedded gold nanoparticles by thermal poling, Applied physics letters 89 (18) (2006) 183121. 
[3] J. Sancho-Parramon, V. Janicki, J. Arbiol, H. Zorc, F. Peiro, Electric field assisted dissolution of metal clusters in metal island films for photonic heterostructures, Applied physics letters $92(16)(2008) 163108$.

[4] A. Lipovskii, V. Melehin, M. Petrov, Y. P. Svirko, V. Zhurikhina, Bleaching versus poling: Comparison of electric field induced phenomena in glasses and glass metal nanocomposites, Journal of Applied Physics 109 (1) (2011) 1.

[5] O. Deparis, P. G. Kazansky, A. Abdolvand, A. Podlipensky, G. Seifert, H. Graener, Polingassisted bleaching of metal-doped nanocomposite glass, Applied physics letters 85 (6) (2004) $872-874$.

[6] M. Beresna, P. G. Kazansky, O. Deparis, I. C. Carvalho, S. Takahashi, A. V. Zayats, Polingassisted fabrication of plasmonic nanocomposite devices in glass, Advanced materials 22 (39) (2010) 4368-4372.

[7] A. Abdolvand, A. Podlipensky, S. Matthias, F. Syrowatka, U. Gösele, G. Seifert, H. Graener, Metallodielectric two-dimensional photonic structures made by electric-field microstructuring of nanocomposite glasses, Advanced Materials 17 (24) (2005) 2983-2987.

[8] V. Janicki, J. Sancho-Parramon, F. Peiró, J. Arbiol, Three-dimensional photonic microstructures produced by electric field assisted dissolution of metal nanoclusters in multilayer stacks, Applied Physics B 98 (1) (2010) 93.

[9] A. Lipovskii, M. Kuittinen, P. Karvinen, K. Leinonen, V. Melehin, V. Zhurikhina, Y. P. Svirko, Electric field imprinting of sub-micron patterns in glass-metal nanocomposites, Nanotechnology 19 (41) (2008) 415304.

[10] I. S. Sinev, M. I. Petrov, A. K. Samusev, V. V. Rutckaia, A. A. Lipovskii, Nanoscale patterning of metal nanoparticle distribution in glasses, Nanoscale research letters 8 (1) (2013) 260.

[11] V. Janicki, I. Fabijanić, B. Okorn, P. Dubček, J. Sancho-Parramon, Selective electric field assisted dissolution as a technique for micro and nano structuring of metal thin films, Applied Physics Letters 113 (18) (2018) 183508.

[12] M. I. Petrov, V. G. Melehin, V. V. Zhurikhina, Y. P. Svirko, A. A. Lipovskii, Dissolution of metal nanoparticles in glass under a dc electric field, Journal of Physics D: Applied Physics 46 (4) (2012) 045302.

[13] O. Deparis, P. G. Kazansky, A. Podlipensky, A. Abdolvand, G. Seifert, H. Graener, Evolution of poling-assisted bleaching of metal-doped nanocomposite glass with poling conditions, Applied Physics Letters 86 (26) (2005) 261109.

[14] J. Sancho-Parramon, A. Abdolvand, A. Podlipensky, G. Seifert, H. Graener, F. Syrowatka, Modeling of optical properties of silver-doped nanocomposite glasses modified by electric-fieldassisted dissolution of nanoparticles, Applied optics 45 (35) (2006) 8874-8881.

[15] Z. Zou, X. Chen, Q. Wang, S. Qu, X. Wang, Electric field assisted dissolution of au rods in gold-doped silicate glass, Journal of applied Physics 104 (11) (2008) 113113. 
[16] Z. Zou, Q. Wang, X. Chen, S. Qu, Direct evidence for electric field assisted dissolution of au nanoparticles on glass surface, Journal of Applied Physics 105 (10) (2009) 103114.

[17] J. N. Hilfiker, G. K. Pribil, R. Synowicki, A. C. Martin, J. S. Hale, Spectroscopic ellipsometry characterization of multilayer optical coatings, Surface and Coatings Technology 357 (2019) $114-121$.

[18] J. Sancho-Parramon, V. Janicki, H. Zorc, On the dielectric function tuning of random metaldielectric nanocomposites for metamaterial applications, Optics express 18 (26) (2010) 2691526928.

[19] M. Hövel, B. Gompf, M. Dressel, Dielectric properties of ultrathin metal films around the percolation threshold, Physical Review B 81 (3) (2010) 035402.

[20] T. V. Amotchkina, M. K. Trubetskov, A. V. Tikhonravov, V. Janicki, J. Sancho-Parramon, H. Zorc, Comparison of two techniques for reliable characterization of thin metal-dielectric films, Applied optics 50 (33) (2011) 6189-6197.

[21] J. Sancho-Parramon, V. Janicki, H. Zorc, Tuning the effective dielectric function of thin film metal-dielectric composites by controlling the deposition temperature, Journal of Nanophotonics 5 (1) (2011) 051805.

[22] O. Stenzel, The physics of thin film optical spectra, Springer, 2015.

[23] D. J. Bergman, The dielectric constant of a composite material-a problem in classical physics, Physics Reports 43 (9) (1978) 377-407.

[24] W. Theiß, The use of effective medium theories in optical spectroscopy, in: Advances in Solid State Physics 33, Springer, 1994, pp. 149-176.

[25] A. R. Day, A. Grant, A. Sievers, M. Thorpe, Spectral function of composites from reflectivity measurements, Physical review letters 84 (9) (2000) 1978.

[26] J. Sancho-Parramon, J. Ferre-Borrull, S. Bosch, M. C. Ferrara, Use of information on the manufacture of samples for the optical characterization of multilayers through a global optimization, Applied optics 42 (7) (2003) 1325-1329.

[27] M. Leitner, H. Peterlik, B. Sepiol, H. Graener, M. Beleites, G. Seifert, Uniformly oriented, ellipsoidal nanovoids in glass created by electric-field-assisted dissolution of metallic nanoparticles, Physical Review B 79 (15) (2009) 153408.

[28] J. Sancho-Parramon, S. Bosch, A. Abdolvand, A. Podlipensky, G. Seifert, H. Graener, Effective medium models for metal-dielectric composites: an analysis based on the spectral density theory, in: Advances in Optical Thin Films II, Vol. 5963, International Society for Optics and Photonics, 2005, p. 596320.

[29] R. G. Barrera, P. Villasenor-Gonzalez, W. L. Mochán, G. Monsivais, Effective dielectric response of polydispersed composites, Physical Review B 41 (11) (1990) 7370.

[30] L. G. Grechko, V. N. Pustovit, K. W. Whites, Dielectric function of aggregates of small metallic particles embedded in host insulating matrix, Applied Physics Letters 76 (14) (2000) 18541856. 
[31] M. Held, O. Stenzel, S. Wilbrandt, N. Kaiser, A. Tünnermann, Manufacture and characterization of optical coatings with incorporated copper island films, Applied optics 51 (19) (2012) $4436-4447$.

[32] T. Giallorenzi, E. West, R. Kirk, R. Ginther, R. Andrews, Optical waveguides formed by thermal migration of ions in glass, Applied Optics 12 (6) (1973) 1240-1245. 